\section{Solveig Wikström}

School of Business, Stockholm University, Sweden

\section{Value Creation by Company-Consumer Interaction}

Company-customer interaction is becoming increasingly uidespread in industrial markets, bringing benefits that are both productive and strategic. This paper looks at the prerequisites for applying the same logic in consumer markets.

The conclusion is that due to new technology and the emernence of more qualified and demanding consumers, the logic is diready appearing in a wider range of industries, with interaction in one or more activities in the value-creating process; in design, production and marketing as well as in the consumption and later destruction of products. But, up to now, the benefits are mainly on the consumer side. There seems to be some potential for considerable strategic advantages for companies, however, provided that their organizational structure is modified, new communication channels are built, the competence of the front-line staff is developed, and the company culture becomes more consumer-oriented.

\title{
Introduction
}

In pre-industrial society, it was often the end-user who made important decisions, such as what was to be made and even how it was to be designed and produced by the craftsmen and store-keeper. In this way, the consumer's knowledge was used for productive ends. In contrast, the customer's role in the mass-consumption era has become much more limited, and the customers are themselves the target for corporate information and persuasion. This is because the company has to sell what it has already produced, which means that the end-user's input is restricted to acceptance or rejection. There is seldom much scope for pre-production interaction. On the other hand, the consumers of mass-produced goods have been favoured when it comes to price, compared with the customer-made alternatives. In other words, mass production has made products and services ever cheaper.

But, as we enter the post-industrial era, conditions are changing dramatically. Fast and flexible new production facilities and the rapid expansion of information technology (IT) have made it possible for producers to interact with many of their customers on an individual basis, and to add a personal touch to their offerings. New possibilities are thus emerging for exploiting the consumer's own knowledge and capability in designing products and services, and thus for making the consumption process more efficient. The logic of custom-made production appears to be emerging in a new shape, and now at costs close to those of mass production.

These changes open up new ways of doing business. In simpler terms, the 
development could be described as a movement towards a much closer relationship between producers and consumers - a sort of joint venture in the marketplace, in which the consumer increasingly assumes the role of co-producer.

Not only have technology and internal ways of working changed, but the whole mental map with its view of the customer's role has also altered dramatically. The customer is no longer regarded as a passive receiver but is coming to be seen as an active and knowledgeable participant in a common process. This is why the company's activities are focusing increasingly on support for the customers's own production, i.e. on their specific value-creating role. The company's role is no longer limited to supporting the customer by providing goods or services. Rather it is a question of designing a system of activities within which customers can create their own value. The company thus complements the knowledge and resources already possessed by its customers, as was the case in the pre-industrial period. From this interaction and co-operation in time and space, a value emerges that is the result of co-production. Compared with the sequential way of working, this clearly implies a shift in perspective, a switch from a producer-and-customer perspective to one of coproduction. (Normann and Ramirez 1994; Wikström et al. 1994).

Close customer interaction and customer co-operation are concepts which have been applied mainly in industrial and service markets. In consumer goods markets, the idea of the consumer as co-producer is much discussed (Toffler 1980, 1983; Grönroos 1990; Davidow and Malone 1992; Gummesson 1993; Pine 1993), but very little is known about what exactly it means in concrete terms and in practice. This paper looks at what companies are doing about inviting the consumers to become co-producers, and what they could be doing. And this brings us to the next question to be addressed. The co-production logic, it is said, generates more value, and new types of value, compared with the sequential mass-production logic (Womack et al. 1990; Milgrom and Roberts 1990; Brown 1991; Badaracco 1991; Wikström et al. 1994; Wikström and Lundkvist 1994). But what exactly is the gain to the participants? And are the gains available in all types of consumer markets, or only in some? In short, what are the prerequisites for such a work logic?

The analysis of these questions below is based on experience of the industrial market, while the theoretical framework is also influenced by knowledge from the same field.

It seems reasonable to me to invoke analogies with the industrial market, since the consumer market is coming increasingly to resemble its industrial counterpart. Consumers are becoming more knowledgeable, as well as more demanding and individualistic in their preferences, while companies have become more flexible. With the support of $\mathrm{IT}$, they are also becoming capable of interacting with many consumers on an individual basis.

\section{Theoretical Framework}

In order to exploit the consumers' knowledge, experience, expectations, wants and needs, and to get some insight into their priorities, their visions and their way of living, there has to be some sort of interaction. And as the consumers become part of the value-creating activities, their specific brands of knowledge will be available on a continuing, day-to-day basis. At the same time, the company possesses 


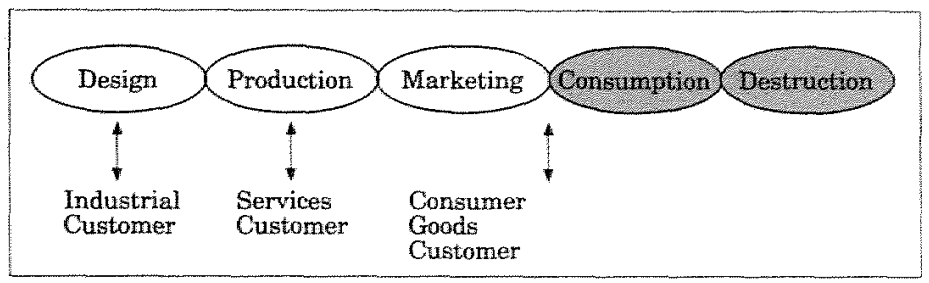

Figure 1. Customer/consumer entry into the value-creating process in different markets. Figure inspired by Carlsson (1990) and Gummesson (1993).

knowledge which can be of value to the consumers in their own value-creating process. From this interaction, a mutual learning process is born.

Interaction means that the consumers now take part in activities and processes which used to be seen as the domain of the companies. But interaction in the valuecreating process also means that companies enter the domain of the consumers and take part in their consumption of the product and even their scrapping of what is left over.

In the service and business-to-business markets, there is a strong focus on relations between provider and customer. What is particularly interesting in both these markets is that the customer enters the value-creating process at an earlier stage than is assumed in consumer goods markets. Figure 1 below illustrates the situation in the three types of market.

The value-creating process consists of a set of activities starting with the design and development of what is going to be produced. Following production, marketing activities bring the finished products to the consumers, who either except or reject them. If the offerings are accepted, then consumption activities occur, followed sooner or later by the destruction of what is no longer suitable for consumption. According to the transaction logic that dominates most consumer goods markets, the division of roles between producer and user is distinct (Normann and Ramirez 1994; Wikström et al. 1994).

The consumer enters the process when the goods are ready for purchase. In the case of services, however, entry occurs during the production of the service, as here the consumer is, by definition, part of the production process. In industrial markets - particularly in markets where the company has few customers to attend to the interaction may start at an even earlier stage, with design and development. Business-to-business company-customer interaction has long been a logic that is widely applied and enjoys strong theoretical support (Hakansson and Snehota 1989; Badaracco 1991; Axelsson and Easten 1991; Forsgren and Johansson 1992; Hammer and Champy 1993; Grabher 1994).

In view of the procedures which are emerging in the service and industrial markets, we must ask ourselves what conditions are persuading the consumer to become part of the design and production activities. And, looking at the interaction from the other end of the process, how can we promote corporate interaction in the traditional consumer domain of consumption and destruction? 
Håkansson and Östberg (1975) ${ }^{3}$ have developed a model defining variables for explaining the interactive way of working. This model, which contains relatively few variables, is based on recognized interorganizational theory and has been extensively tested; it has also demonstrated good predictive capability. With the help of this model, which is briefly described below, and with perspectives from organizational theory and the theory of learning, the conditions for interaction in consumer markets will be analysed.

In this analysis, inspired by the authors mentioned above, I define co-production (collaboration, consumer co-operation etc.) as company-consumer interaction (social exchange) and adaptation, for the purpose of attaining added value.

According to Hakkansson and Östberg, the degree of social exchange and adaptability (co-production) is decided by:

(1) Perceived uncertainty and perceived benefits. The greater the uncertainty, the more social exchange is needed; and the greater the number of benefits expected, the greater the willingness to adapt.

(2) Relevant situational variables in this context are concerned with the nature of the exchange, the characteristics of the two parties involved and the environment.

(i) Relevant characteristics of the exchange include the position on a standardization-complexity scale and the volume exchanged, where high complexity and great volume tend to promote interaction.

(ii) Important characteristics of the parties concerned include perceived ability to reduce each other's uncertainty, the respective technologies (for adapting) and the organization structures (facilitating buyer-seller social exchange and information-processing).

(iii) The characteristics of the environment (the market) can be defined by a fourpart matrix, namely homogeneous-heterogeneous and stable-dynamic, where heterogeneity and dynamism tend to trigger interaction.

Thus far, Hakkansson and Ostberg, but we have to go further. Given the coproducer conception of the consumer, many established ideas and perspectives become invalid, as noted above, and have to be replaced by new ones.

(1) The attitude that sees the company as the active party persuading the consumers to buy what has already been made, with the consumer as a passive object whose only response is to buy or not to buy, has to be challenged. Now the consumer too is regarded as an active participant, who has a say in what is going to be produced.

(2) The assumption that companies produce and consumers use is thus replaced by the idea that both are active participants in the value-creating process.

(3) The view that the company's role is to satisfy the consumers' wants and needs is also challenged. Instead, the company's task is defined as making a contribution to the consumers" own value creation, in which the company's offerings are a vital ingredient. Thus when consumption is seen as a productive process, the consumers themselves perform the final and crucial activities in the value-creating process. For instance, they drive the car, cook

\footnotetext{
${ }^{1}$ The model was developed as part of the IMP research programme at Uppsala University, and has now been further elaborated (see e.g. Håkansson and Johansson 1988; Hâkansson and Snehota 1989; Hallen and Johansson 1989).
} 
the meal, take the photos, apply the make-up etc. In order to make this process more efficient, the consumers may have to extend their activities to design, production, etc. This assumption finds support in anthropology. McCracken, for example, claims that in order to understand the consumer role, we have to take a much broader view of consumer behaviour than is implied by just buying and consuming (McCracken 1988).

(4) The concept of the "offering" is replacing that of products and services, since much of the company's input is now a mix of tangibles and intangibles.

(5) In this analysis, the concept of interaction, rather than information and persuasion, is pivotal. This is because the most efficient way of increasing a knowledge base seems to be through interactive processes, or let us say through collaboration with a view to learning. This is where the model's benefits of interaction and adaptation appear, albeit not always explicitly.

(6) As regards learning, it is useful to distinguish between static and dynamic interaction. The static type is highly programmed, for example the interaction at a McDonalds counter or a supermarket check-out, where there are standard answers to customers' questions which do not generate much learning. On the other hand, in solving a complex problem - perhaps company and customer meet to set up a personal fitness programme or work out an insurance policy to cover a family's needs - dynamic interaction occurs. The exchange of information which takes place opens the way to extensive learning. This interactive learning "enhances the innovative capability of the producer and the competence of the user" (Lundwall 1993, p.56).

(7) Organization theory (Argyris and Schön 1980) and the theory of learning (Senge 1990) suggest that learning takes place on two levels. Adaptive learning leads to doing what you already do, but in a better and more rewarding way. In marketing terms, this means attaining a better fit.

Generative learning involves insight, whereby established norms are challenged. New ways of performing are envisaged, which may result in new types of offering, or in new parts for present offerings. Generative learning means that people can accomplish things which they couldn't do before. The process of learning, be it adaptive or generative, is based on reflection. People act, then reflect upon what they are doing and what they experience. This can lead to acting in new ways according to new insights. This is how learning is manifest.

A last point to bear in mind here concerns the purpose of the interaction. In market research, for example in focus groups, company-consumer interaction is arranged. This ad hoc type of interaction is not what the present analysis is about. Instead the focus here is on interactions which are part of an exchange, interactions from which both parties will benefit. We can now examine this type of interactive exchange within the different activities of the value-creating process.

\section{Acts of Interaction and Adaptation}

The analysis of company-consumer interaction and adaptation is based on examples 
from the relevant literature and cases from our ongoing research ${ }^{2}$ In our research for consumer companies involved in some sort of interactive relation with their endusers, we found two cases; the Volvo Car Corporation and IKEA. These are both established companies in industries working according to a mass-production logic.

As the examples and cases will demonstrate, the interactive way of working is beginning to appear in a variety of industries in the consumer market. What is more, the examples suggest that the interaction seldom takes place in all the activities of a value-creating process, but occurs in one or two of them only. The analysis is thus conducted separately for each activity, starting with design.

\section{Design and Development}

Consumer involvement in design seems to be growing rapidly. In this collaborative work, the design is created either by combining standard modules offered by the supplier, or by following personal specifications. A wide variety of products and services are now being customized. The purpose is obvious, namely to meet individual needs, wants and requirements. This work logic has even been given its own label - mass customization or MC. (Peppers and Rogers 1992; Pine 1993). The $\mathrm{MC}$ concept explains why interaction in design has been so extensively adopted. As production becomes more flexible and new communication technologies are available, it becomes possible to combine the old mass-production logic with individual preferences. This is why many companies are able to offer individually designed offerings at the same or almost the same price as the mass-production mode can offer.

Cars are made this way. Volvo, for instance, customize their cars from hundreds of thousands of modules, which make it possible for Volvo to offer a huge variety of details within the overall design of this car. This even applies to software such as financing and insurance. When the customer and the dealer design the car together, they try out alternative details and the appearance of the car as a whole on the computer screen, before decisions are made. Once a document with a specification of all the details of the car has been signed, and the delivery time checked with the manufacturing function, the car is given its own identity number and its production can start on the assembly line.

IKEA, which relies heavily on mass production, economies of scale and low cost, has now started to experiment with customization. The company offers customized kitchens at a standard price. Like Volvo, IKEA work out solutions with the support of a CAD system. A specially trained salesperson designs alternative solutions which are shown in three-dimensional pictures on a computer screen. Printouts can also be made if the customer wants to consider several alternatives at home. When the decision has been made, a document is printed out specifying all the details, including delivery time, setting up the kitchen, insurance and customer service.

IKEA has started to experiment with the customization of individual pieces of furniture as well. They have realized, they say, that their customers no longer want

\footnotetext{
${ }^{2}$ The research programme took off with "Value creation by company-consumer interaction" in Wikstrom et al. (1994, Swedish version 1992). The programme has resulted in several conference papers, two of them currently in press. The cases used in the present paper are from a Masters Thesis prepared in connection with this programme (Ekström and Schmitt 1995).
} 
to see furniture identical to their own in their neighbour's home. So, with the support of a special CAD computer in the store, customers are given the opportunity to design their own sofas by combining different fabrics, colours, models etc. The system works in very much the same way as in the previous examples. When the decision has been made on the computer, an order goes into production automatically, and the customer receives a printed document with all the details and specifications chosen.

Not only expensive products but also small items are being customized. Estée Lauder has developed a system whereby the retailers customize cosmetic products according to the customer's type of skin (Wikström 1993). The analysis is made with the help of a computerized diagnostic system, and the mixture is made up in the store according to the special formula suggested by the analysis. The customer tries the formula and, depending on the results, the same formula will be used next time or changes will be made until a satisfactory solution has been reached. This system is offered in many European countries and in the USA. It has been considered too expensive for Swedish consumers.

Pine (1993) reports on a variety of examples of mass customization on the US market. He describes Personic's in-store cassette system, which means that customers can have their favourite songs and pieces of music combined on their individually designed cassettes, at a cost equivalent to mass-produced cassette tapes. Spectacles provide another example of customization. These used to be produced in central factories in batch orders from hundreds of optometrics, but now Lenscencrafters, Eyelab, Eyworks and a host of other US operations mass customize eyeglasses within the hour.

Customization is applied to many other personal products and services. Bicycles are made this way, as are chairs designed for comfort and many items of clothing. A rising proportion of what used to be highly standardized packaged tours are going the same way, and the same applies to insurance and banking services. In some cases, even sports shoes, magazines and books are available in masscustomized versions.

Collaboration in design seems to refer mainly, to go by the available examples, to well-established products and services, where the most obvious consumer benefit is that of personal fit. Here, in contrast to the industrial markets, interaction has very little to do with reducing uncertainty and risk. On the contrary, buying what already exists and can be checked in advance, involves less risk than ordering something which is still little more than a vision. This can be said of your moduled car, your designed dress, the special formula for your skill or the sofa you designed yourself. Will it meet your needs and expectations when it's in place? However, the risk inherent in having standardized offerings "tailor-made" is being increasingly reduced by new technology, whereby the design can be visualized in advance in three-dimensional images - as the IKEA and Volvo cases have demonstrated. But other technologies are emerging which go even further. With the help of virtual reality, you can try on the dress, drive the car and walk about in the kitchen, before any of them exists. This, of course, greatly reduces the consumer's risk.

The most important precondition for this work logic, however, is that the companies should have a flexible production system. They must be capable of producing what is designed in a one-to-one batch, and do so at a cost that does not exceed that of the standardized production, or, if so, by very little only. 
There is still another vital prerequisite for realizing the interactive design in a productive way. I am referring to the organizational structure and the way in which the communication channels are arranged. Decentralization and the empowerment of front-line personnel appear crucial. The Volvo car-dealer, for instance, has to know all the design alternatives which the company is capable of delivering, all the most suitable combinations, the cost of the alternatives, current changes in production and so on. This is made possible by a special computer support system, but also by the fact that there is on-line communication with other departments whenever some new point arises in the front-line interaction. Another vital ingredient in productive interaction is the feedback of knowledge acquired by the front line in collaboration with the consumers. What organizational arrangements are there to guarantee that this knowledge will reach the relevant actors inside the company? And how is this knowledge valued? Will it be used?

Both Volvo and IKEA emphasize the value of information from their front-line customer interaction. And both express frustration at not having found a way of introducing this feedback.

"If something goes wrong, the information goes to the sales people, but it doesn't go any further. Our sales support system is not organized so that the information can reach the management level, but our ambition is to develop such a system." (Volvo 1995).

IKEA puts it in a similar way:

"It is our ambition to build some sort of feedback channel from the front line to product development and to other parts of the organization." (IKEA 1995).

We know from experience of industrial markets that conditions in the market affect the co-operation; interaction and adaptation are more likely in heterogeneous and dynamic markets. In consumer markets, the effect inclines towards the opposite; interaction and adaptation occur most frequently in well-established homogeneous markets of limited dynamism. The situation is, rather, that interaction and adaptation seem to make the market more heterogeneous and dynamic, which may explain why companies are moving towards this logic. By interacting, they can differentiate their offerings.

\section{Production}

Consumers have long taken part in production, under the do-it-yourself flag. By taking over part of the process, consumers can cut costs and save money. Economic reasons have thus been the dominant driving force.

Now, however, consumers have started to engage in do-it-yourself in new areas and for completely different reasons. By managing activities themselves, instead of leaving them to a supplier, consumers acquire a sense of freedom. They become independent of time and place. Examples of such do-it-yourself tools and systems include new telephone systems which offer answering services, the transfer of calls, automated wake-up calls and telephone conferencing. Mobile telephoning, the teller 
machine and on-line banking, the personal computer with fax and publishing facilities, programmes for self-care which replace hospital care, are other examples. The new facilities and systems enable the consumers to do things which they couldn't do before. The facilities and systems are mainly based on new technology, and their success depends greatly on their user-friendliness. In all do-it-yourself production, the consumers need clear instructions, but they have no advance experience of the new complex systems and are bound to feel uncertain, which means that extensive interaction and adaptation are crucial, initially at any rate.

While the traditional do-it-yourself in production was driven mainly by economic benefits, the new type must have other incentives. As consumers become independent of place and time in connection with the activities, they also become more flexible. Besides this practical reason, there may also be a psychological dimension. People can do new things on their own, which makes the feel empowered. And they can do things when it suits them.

From the company's point of view, including the consumers is a way of creating new business. Success in this context has less to do with specific organizational prerequisites and more to do with new infrastructures, appropriate systems design, and with the amount of consumer learning that the system generates. In the initial stage, a lot of interaction is needed, as the transactions occur in a highly differentiated and dynamic market where the consumers have little or no previous experience. Thus the need for interaction and adaptation is very much the same as in heterogeneous and dynamic industrial markets.

\section{Marketing}

By tradition, the marketing function represents the simplest form of communication, involving a sender, a message and a receiver. The much-talked-of "direct marketing" has changed the scope of the message; marketing is now directed at a database of potential customers of high-buying propensity, and the transaction takes place between the manufacturer and the end-user. But so far, little more interaction has been introduced (Howard 1989).

New media have made interaction possible, however, and have even turned the dialogue round. The initiative is now with the consumers. With interactive TV and $\mathrm{CD}$ ROM, consumers can choose the areas that interest them, and can then look more deeply into the varieties within those areas; they can ask questions and get answers in several rounds. Even if the answers are programmed, the range of alternatives can be very large, which makes for interaction verging on the dynamic.

The idea that the consumer should assume an active role is much more challenging in marketing than in design and production. With excess capacity in the mass-production system, marketing has become vital. Investment in marketing can be expected to become increasingly profitable, with a resulting overload of information and persuasion. In this "noisy" world, it should appeal to the consumers to be able to control the information flow and to choose the kind of information which is relevant to them. New interactive media provide this opportunity, and with the appearance on the scene of independent information brokers, like Netscape and Compu-Serve, a supply of information structured in consumer terms has become available. 
The benefit to the consumers lies in the possibility of more efficient choice, while the cost is associated with learning to operate the new information systems. On the company's side, developments are driven more by the whip than by the carrot. Once the system has become widespread, no individual company will have any choice but will have to follow the market-driven flow; companies will have to adapt and change their marketing strategies accordingly.

At the same time, however, a certain part of the marketing is moving in the opposite direction - something which is typical of our postmodern era built on paradoxes. The marketing of images is a growing trend (van Raaij 1993; Bouchet 1994; Firat et al. 1995). Products and services increasingly build on images of lifestyles and ways of living, of which the offering is a part. The attraction of this type of marketing, it is said, lies in the consumers' use of the marketed image as an ingredient in building their own self-images. However, this means that they are using the marketing as input into their own value creation, without there being any buyer-seller interaction.

It is obvious that new technology may neform the marketing, but it is too early to have an opinion about exactly how the future will turn out. But, it certainly seems likely that it will involve even more activities on the part of the consumers, and more interaction.

\section{Consumption}

Interaction at the consumption stage turns in another direction. Here it is the role of the company that will be extended. The consumer, of course, is the dominant actor. In this phase, the consumers create their own ultimate value. This can also be seen as an act of production ${ }^{3}$, and in analogy with industrial markets, the supplier's role should be to support the consumers' own activities.

Traditionally, the supplier's activities at this stage are classified under the "aftersales" or "customer" service label. What is known as after-sales service fulfils two quite different functions; one is to receive complaints and to correct faults, while the other is more proactive and focuses on helping the customer to get more value out of the process. Given the quality improvements currently being made, the complaints function is likely to decline in importance while support becomes more important.

In the case of small items of consumer-packaged goods, the most direct and usual way for a company to interact is to establish a free helpline, on which the consumer can reach the supplier. Most companies do, in fact, have such a function, but very few seem to use it to its full potential (Rapp and Collins 1990; Fonell 1991; Haglund and Östberg 1995). Nestlé provides an illustrative example of how the consumers can be encouraged to participate in this way in dynamic interaction with the company. With their baby foods, Nestle offer the customer the opportunity, 10 hours a day and 6 days a week, to talk to a licensed dietician on a free helpline about a baby's eating requirements.

In the case of household durables or of more expensive and complex items, the

'Becker (1965) is very explicit about the consumers' productive role and the postmodernist approach comes to the same conclusion, but from another perspective; the consumers create their own reality (van Raaij 1993; Bouchet 1994; Firat et al. 1995) 
free helpline is classed as customer service. As most household durables today are mature products which do not provide much stimulation, maintenance - to keep them working well - is all the more important. This is why the service function and the service worker have such a strategic role in maintaining relations with the consumers. Good after-sales service based on dialogue guarantees satisfied and loyal customers, by ensuring that the consumers get more use out of their tools.

This depends on keeping the tools in working order and on the consumers knowing how to operate them properly. Further, such interaction provides a valuable source of knowledge for the company when it comes to redesigning the next generation of offerings - provided that the information reaches the relevant actors.

In the case of yet more complex products and services, such as new electronic items, sports equipment, fitness and health care systems, artistic performances, educational programmes etc, an open telephone line may be helpful but does not allow for sufficient support. An awful warning, albeit not a unique one, is provided by a leading multinational consumer electronics company, which launched a new telephone. The product was very sophisticated and offered several new functions, which meant it also called for learning on the part of the consumers. The manual, like most manuals written by experts apparently for other experts, did not give much help. Consequently, the customer-service line, which was only open during office hours, was immediately blocked and was of little or no use to the many consumers asking for advice.

An example of the opposite is provided by some small retailers in, for instance, electronics and sports equipment. A value check accompanies the product, entitling the customer to take part in a special course to learn how to use the advanced camera, the new pair of Telemark skis or a new aerobics bicycle. The situation is much the same in the case of an IKEA kitchen; free consultation about designing the kitchen is part of the offering.

The benefit to the consumer of having an interactive channel open to the supplier is obvious. Having support and advice available during the consumption stage means that the consumption process can generate more value, while at the same time risk and uncertainty are being reduced. The benefit to the companies is also obvious. Extending the interaction into the consumption phase means building up long-term relations with the customers, which should help to promote the next transaction perhaps even more efficiently than any marketing campaign. The consumers develop trust in a company which gives them support in their consumption, for example by keeping channels open for instant and reliable information, by providing fast service at a reasonable cost, by having spare parts available, and by providing support at the destruction stage.

In order to take an active part in the consumption stage, companies have to adjust their organizations. Many companies do seem to have channels of some sort, but they are not well kept. Studies have repeatedly shown this to be a neglected area, which causes much frustration among consumers, whose confidence in the companies is undermined (Fonell and Westbrook 1984; Wikström 1984; Rapp and Collins 1990).

In consumer markets, interaction at the consumption stage seems highly relevant, irrespective of the market structure. In dynamic areas, however, the need for support seems to be even more urgent than in mature markets. 


\section{Destruction}

With growing environmental awareness, waste from consumption is no longer perceived as an externality. The junk car, the scrapped washing machine, the empty bottle or the carton all have to be taken care of by those who have been involved in their production and use. The post-consumption stage which used to be anarchic, has simply been incorporated into the commercial system of production and consumption.

Ambitions are growing, however, and the question is no longer how the junk can be rendered harmless, but rather how it could be utilized and how the recycling process should be organized. For this purpose, company and consumers have to interact and adapt. Here their interaction reveals very little of a one-toone relationship. It looks more like a muddling-through process, involving a third party - the government authorities - as well. Systems for destruction or recycling have to be developed. This is a company task, and sometimes a government one. Consumers have to take part in running these systems. They have to bring in their ancient car for scrapping, for example, or return their bottles and cans, while the sorting of household waste has become increasingly common.

If a system doesn't work, however, and the goals which are set up are not being met, then new efforts have to be made. The product can be changed; perhaps by using new and more environmentally friendly material, new systems can be set up, and so on. If it still doesn't work, the product may even be banned. This applies to cans in the brewery industry, for instance; if returns do not reach a certain level, then other types of packaging have to be used.

In these destroying activities, company and consumers are forced to interact and adapt, which of course makes this situation different from the other stages in the value-creating process. At this stage, value creation has a further purpose, one that is collective, namely to achieve a cleaner and healthier environment and a more efficient use of finite resources.

As far as I can see, the process of interacting, adapting, experimenting and learning is more far-reaching at this stage, where the driving force is a deep concern for the environment and the future, than at any of the stages when the impetus comes from attaining private benefits.

\section{The Interaction Phenomenon: Some Reflections and Conclusions}

The examples of company-consumer interaction and adaptation at the different stages in the overall value-creation process, means in reality that the actors are expanding their traditional roles. Consumers become active partners in design, production and marketing, and companies become more involved in consumption, while both partners are now involved in the destruction stage (See Figure 2). This seems to hold true irrespective of what is being created; generally a tangible product or an intangible service.

As we have seen, the consumer role is no longer limited to the transaction and consumption stages, or to participation in market research. We have noted a growing number of examples of the way consumers are being invited to take a more active 


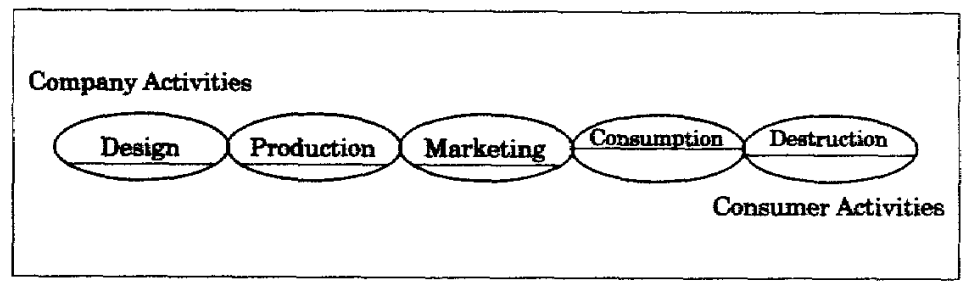

Figure 2. Extending the company-consumer inferaction in the value-creating process.

role in design, as well as in production and even in marketing. And, looking at it from the opposite side, we see that companies can increase their value creation by extending their activities into the traditional consumer domain of consumption itself. This means that company-consumer interaction occurs at all stages in the value-creating process - or, let us say, it could do so. There are already examples of ways in which this can be done, such that the interaction gives rise to productive knowledge and, in a few cases, generative knowledge as well. I will return to this point.

In light of the above examples of company-consumer interaction, the initial model of the actors' entry into the value-creating process can now be modified. Figure 2 shows the extended domain of company and consumer.

The company is still the dominating actor in design and production, and is still the main provider of information as part of the marketing activities. But the consumer seems poised to take part in design and in deciding what information to search for, which will mean a rapid decline in mass-marketing as well as direct marketing. According to Figure 2, the company will be providing support for the consumption activities and will also offer support at the destruction stage.

How can these interactive processes be understood in terms of the interactive model introduced above? What enhances or obstructs interaction? And under changing conditions, in what direction will the future most likely develop?

The examples show that companies do different things in different industries to encourage consumers to interact with them, and that interaction generally takes place in one or two activities only, in the value-creating process as a whole.

At the design stage, one type of interaction concerns mass customization. With the help of flexible production and computerized flows of information, standardized offerings are designed according to individual needs and preferences. This applies mainly to highly personal products and services.

At the production stage, the do-it-yourself approach has a long history in the case of simple tasks. However, there is a new trend according to which the company develops tools and systems enabling the consumer to do things which they were unable to do before; banking from home, making payments without cash, printing, faxing mobile telephoning etc. By empowering the consumers to do things themselves, new and fast-growing industries have developed.

Inviting consumers to act and take the initiative in marketing is something new, made possible by support from information technology. CD ROM and interactive TV gives consumers the chance to choose the type of information they need in an efficient way, giving more - and more detailed - information as necessary. This interactive way of marketing should be possible for all kinds of consumer offerings, 
irrespective of type. Company-consumer interaction in consumption is also an established area. Free helplines are a routine offering for small ticket items, as customer service is for more complex offerings. But both are seldom used to their full potential by the companies.

The aim of this interactive way of working is thus to make it easier for consumers to achieve more value. The examples show that the work logic is available in all types of consumer markets, in one activity or another. Interaction with consumers has benefited from new technology, and probably also from the fact that consumers are becoming more capable, more knowledgeable and more demanding, while educational levels have increased and the information society as a whole has matured.

The interactive way of working, it is said, generates types of value other than those created by the mass-production logic. How much of this is attainable in consumer markets? The benefits to the consumers are very direct; a better fit and a more efficient use of input. And the companies acquire a short-time competitive advantage by serving their customers in a more efficient way. Another benefit that accrues in the industrial markets is generative knowledge. With relatively few customers to attend to, the interaction often starts with the solving of problems, which provides an opportunity for much deeper interaction and more advanced learning. In these activities, it is not only sales and service staff but also design and production people who interact with the customers, which means that all these people learn directly from their often close and dynamic co-operation with many of their clients.

In consumer markets, the interaction has to be programmed and is thus generally rather static due to the large numbers involved. Moreover, from the company side, it is mainly handled by the sales and service staff. These people traditionally occupy fairly low positions in the company hierarchy; they have little knowledge of what is going on in other parts of the company and have little authority. There is usually very little scope for them to reflect upon their highly programmed work or to learn from it. And what they do see and learn tends to remain at the front line without being used, as there are no channels to carry the information back into the company. Companies which have gone a long way towards consumer interaction, like Volvo and IKEA, are aware of this problem but don't know how to solve it. In contrast to the industrial market, this is the weakest point when it comes to acquiring generative as well as strategic knowledge as part of the consumer-interaction process. Thus, organizational learning remains limited.

For consumer companies to benefit from learning through interaction, organizational innovations are clearly needed. The role of the front-line people, for example, has to be redefined and their competence improved. Perhaps these people should be rewarded not only for how much they sell or the number of services they render or complaints they handle, but according to the amount of relevant information they feed back into the organization. More scope for reflection and new channels of information are also needed. But this in turn calls for a mental company turnaround, or what is popularly called business re-engineering. The main prerequisite for moving in this direction, however, is that companies should come to see the consumers, with their experience, knowledge, visions and preferences as an extremely valuable resource in their own production, and one to which access should be continually available on a day-to-day basis. 


\section{Acknowledgements}

I am indebted to Dennis Snower for his insightful comments, and have benefited from seminar participants at the Marketing Academy of Stockholm School of Business. I thank Nancy Adler for her improvements of the English.

\section{References}

Argyris, C. and Schön, D. (1978), Organizational Learning: A theory of Action Perspective, Reading MA., Addison-Wesley Publication Company.

Axelsson, B. and Easten, J. (1991), Industrial Network - The New Reality, London, Routledge.

Badaracco, J.L. (1991), The Knowledge Link: How Firms Compete Through Strategic Alliances, Boston, MA, Harvard Business School Press.

Becker, G. (1965), "A Theory of the Allocational Time". The Economic Journal, LXXV, No.299, pp.493-517.

Bouchet, D. (1994), "Rails without Tries. The Social Imaginery and Postmodern Culture. Can Postmodern Consumption Replace Modern questioning?" International Journal of Research in Marketing, 11, pp.405-422.

Brown, J.S. (1991), "Research that Invents the Corporation". Harvard Business Review, January/February (1992), pp.102-111.

Davidow, W.H. and Malone, M.S. (1992), The Virtual Corporation, New York, Harper Collins.

Ekström, B. and Schmitt, S. (1995), Interactive value creation in consumer markets (in Swedish), Master Thesis, Stockholm University, Sweden.

Firat, T., Dhalakia, N. and Venkatesh, A. (1995), "Marketing in a Postmodern World". European Journal of Marketing, 29, No.1, pp.40-56.

Fornell, C. (1981), "Increasing the Organisational Influence of Corporate Consumer Affairs Departments". The Journal of Consumer Affairs, 5, No.2, pp.191-207.

Fonell, C. \& Westbrook, A. (1984), "The Vicious Circle of Consumer Complaints". Journal of Marketing, 48 pp.68-78.

Forsgren, M. and Johansson, J. (Eds) (1992), Managing Networks in International Business, Philadelphia, Gordon \& Brecht.

Grabher, G. (Ed) (1994), The Embedded Firm. On the Socioeconomics of Industrial Networks, London, Routledge.

Grönroos, C. (1990), Service Management and Marketing. Managing the Moments of Truth in Service Competition, Lexington, MA, Lexington Books.

Gummesson, E. (1993), Quality Management in Service Organisations, New York, ISQA.

Haglund, G. and Ostberg, M. (1995), Konsumentkontakt. Master Thesis, Stockholm University, Sweden.

Hallén, L. and Johansson, J. (1989), "Network or Relationships in International Industrial Marketing". In: Advances in International Marketing, Volume 3. (Ed) Cavasgill, S.T. (Connecticut), JAI Press, pp.3-5, 95-96, 195-197.

Hammer, M. and Champy, J. (1993), Reengineering the Corporation. A Manifesto for Business Revolution, London, Nicholas Brealey Publishing. 
Howard, J.A. (1989), Consumer Behaviour in Marketing Strategy, Englewood Cliffs, Prentice Hall.

Håkansson, H. and Johansson, J. (1988), "Formal and Informal Cooperation Strategies in International Industrial Networks". In: Cooperatize Strategies in International Business. (Eds) Contractor, F.J. and Lorange, P. (Lexington, MA), Lexington Press.

Håkansson, H. and Snehota, I. (1989), "No Business is an Island: The Network Concept of Business Strategy". Scandinavian Journal of Management, 5, No.3, pp.187-200.

Håkansson, H. and Östberg, C. (1975), "Industrial Marketing: An Organizational Problem". Industrial Marketing Management, 4, Nos 2/3, pp.109-122.

Lundvall, B. $\AA$. (1993), "Explaining Interfirm Cooperation and Innovation: Limits of the Transaction-Cost Approach". In: The Embedded Firm. (Ed) Grabher, G. (London), Routledge, pp.52-64.

McCracken, G. (1988), Culture and Consumption, Bloomington, Indiana University Press.

Milgrom, P. and Roberts, J. (1990), "The Economics of Modern Manufacturing; Technology, Strategy and Organisation". American Economic Review, 80, No.3, pp.511-527.

Normann, R. and Ramirez, R. (1994), Designing Interactive Strategy, New York, John Wiley \& Sons.

Peppers, D. and Rogers, M. (1993), The One to One Future. Building Relationships. One Customer at a Time, New York, Doubleday.

Pine II, B.J. (1993), "Mass Customization". The New Frontier in Business Competition. (Boston, MA), Harvard Business School Press.

Rapp, S. and Collins, T. (1990), The Great Marketing Turnaround, Prentice Hall.

Senge, P. (1990), The Fifth Discipline. The Art and Practise of the Learning Organisation,

New York, Doubleday \& Curreancy.

Toffler, A. (1980), The Third Wave, New York, William Morrow.

Toffler, A. (1983), Previews and Premises, London, Pan Books.

van Raaij, F. (1993), "Postmodern Consumption". Joumal of Economic Psychology, 14, pp.541-563.

Wikström, S. (1993), "Renewal and Growth of Swedish Industries" (In Swedish). SOU (The Swedish Government Official Reports), 16, Enclosure 2.

Wikström, S. (1984), "Consumer Dissatisfaction; Scope and Policy Implications". European Management Journal, 2, No.2, pp.48-56.

Wikström, S. and Lundkvist, A. (1994), The Role of Information Technology in Interactive Business Development. Book Manuscript in Swedish.

Wikström, S. et al. (1994), Knowledge and Value. The Company as a Knowledge Processing and Value Creating System, London, Routledge.

Womack, J.P., Jones, D.T. and Roos, D. (1990), The Machine that Changed the World, New York, Macmillan Publishing. 
() of Journal of Marketing Management is the property of Westburn Publishers Ltd or its licensors and its content may not be copied or e-mailed to multiple sites or posted to a listserv without first obtaining the copyright holder's express written permission. However, users may print, download, or e-mail articles for individual, non-commercial use only. This article has been reproduced by EBSCO under license from Westburn Publishers Ltd. 